\title{
Temperature-dependent thermal conductivity and viscosity of synthesized $\alpha$-alumina nanofluids
}

\author{
Janki Shah $^{1} \cdot$ Mukesh Ranjan ${ }^{2}$ Vipul Davariya ${ }^{3} \cdot \operatorname{Sanjeev~K.~Gupta~}{ }^{4}$. \\ Yogesh Sonvane ${ }^{1}$ (D)
}

Received: 20 July 2017/ Accepted: 4 September 2017/Published online: 24 October 2017

(c) The Author(s) 2017. This article is an open access publication

\begin{abstract}
In the present work, we focused on the thermal conductivity and viscosity of the synthesis as well as characterize metal oxide $\alpha-\mathrm{Al}_{2} \mathrm{O}_{3}$ nanoparticles suspended in distilled water:ethylene glycol (60:40) ratio based stable colloidal nanofluid. The band gap of the $\alpha-\mathrm{Al}_{2} \mathrm{O}_{3}$ with and without surfactant is 4.42 and $4.59 \mathrm{eV}$, respectively. The results show that nanoparticle with polyvinyl alcohol surfactant has smaller crystalline size $(\sim 23 \mathrm{~nm})$ than without surfactant $(\sim 36 \mathrm{~nm})$. The synthesized nanofluids have good stability after 15 days of synthesis which is characterized by zeta potential analyzer. Thermal conductivity and viscosity are measured for 0.1 and 0.5 $\mathrm{wt} \%$ concentration of alumina for with and without surfactant. The concentration of particles and added surfactant are responsible for stable fluid, thermal conductivity enhancement, and viscosity of nanofluid with respect to temperature. Therefore, the novel combinations of characterized properties of $\alpha-\mathrm{Al}_{2} \mathrm{O}_{3}$ nanofluid has proved to be the best thermally stable heat transfer fluid compared to conventional cooling fluids.
\end{abstract}

Sanjeev K. Gupta

sanjeev.gupta@sxca.edu.in

$\triangle$ Yogesh Sonvane

yas@phy.svnit.ac.in

1 Advanced Materials Lab, Department of Applied Physics, S.V. National Institute of Technology, Surat 395007, India

2 FCIPT, Institute for Plasma Research, Sector-25, Gandhinagar 382044, India

3 Research and Development Lab, Vigor Lifesciences, Ahmedabad 380009, India

4 Computational Materials and Nanoscience Group, Department of Physics, St. Xavier's College, Ahmedabad 380009, India
Keywords $\alpha-\mathrm{Al}_{2} \mathrm{O}_{3}$ nanoparticles $\cdot$ Nanofluid $\cdot$ Thermal conductivity $\cdot$ Viscosity

\section{Introduction}

Ultrahigh cooling performance of a system is very important in many cases, for example nuclear reactors, power plants, refineries, process equipment, and petrochemical (Han 2008). Furthermore, in the industrial arrangements, heat should be transferred as an input energy to the system or should be degenerated from the system (Jang and Choi 2006). Operational and safety criteria are mainly depend on thermal performance of any system (Maïga et al. 2006). A nanofluid is a promising material, which is a stable suspension of nanoparticles diluted in base fluid with particle size generally less than $100 \mathrm{~nm}$. Nanofluids have unique properties of higher thermal conductivity, better stability in comparison with micro-fluids and also cause less damage due to the increase in pressure drop and erosion of pipes.

The progress in research on nanofluid logically increased since the thermal conductivity enhancement was reported some years back (Xie et al. 2002a, b). Lacking perception of the detailing and the mechanism, stability of nanofluids further constrains their applications (Wong and De Leon 2010; Manikandan et al. 2014; Yi et al. 2009). Especially, $\mathrm{Al}_{2} \mathrm{O}_{3}$ nanoparticles have excellent dispersion properties in water as well as in ethylene glycol and make stable suspensions (Eastman et al. 1996). In addition, alumina is very well known because of its useful properties such as high stability, high hardness, high insulation as well as transparency (Akbar and Butt 2015). Alumina has different metastable phases depending on annealing 
temperature such as $\eta, \gamma, \delta, \theta, \beta, \kappa, \chi$, and $\alpha$-alumina. As stated by Gitzen (Karaman et al. 1997), phase transformation $\gamma-\mathrm{Al}_{2} \mathrm{O}_{3}$ to $\delta-\mathrm{Al}_{2} \mathrm{O}_{3}$ accrues when annealing temperature is above $800{ }^{\circ} \mathrm{C}$. As well as $\delta-\mathrm{Al}_{2} \mathrm{O}_{3}$ phase to $\theta$ $\mathrm{Al}_{2} \mathrm{O}_{3}$ phase changes during calcination above $900{ }^{\circ} \mathrm{C}$, and $\theta-\mathrm{Al}_{2} \mathrm{O}_{3}$ transforms to $\alpha-\mathrm{Al}_{2} \mathrm{O}_{3}$ at most stable phase of alumina, when calcined above $1100{ }^{\circ} \mathrm{C}$ mostly $1200{ }^{\circ} \mathrm{C}$ (Amirshaghaghi and Kokabi 2010).

Kole and Dey (2010a, b) synthesized various suspensions of $\mathrm{Al}_{2} \mathrm{O}_{3}$ nanoparticles in the range of $50 \mathrm{~nm}$ which are applied in car engine as coolant fluid. This depends on concentration of nanoparticles and temperature increment 10-80 ${ }^{\circ} \mathrm{C}$. Zamzamian et al. (2011) has measured heat transfer increment in $\mathrm{Al}_{2} \mathrm{O}_{3}$ diluted in ethylene glycol (EG) nanofluids. Patel et al. (2010) has also proposed model for enhancing thermal conductivity by experiment. They measured the thermal conductivity of a nanoparticle enhancing with decreasing volume concentration, which is showing a non-linear relation with particle volume fraction (Mintsa et al. 2009). Sundar et al. (2013a, b) assessed thermal conductivity of water and in addition ethyleneglycol-based $\mathrm{Al}_{2} \mathrm{O}_{3}$ nanofluids for particle volume concentration up to $0.8 \%$ relate to temperature from 15 to $50{ }^{\circ} \mathrm{C}$. They likewise clarify connection in view of the experimental data for the estimate enhancement of thermal conductivity of nanofluids.

The objective of the current study was to establish the effect of surfactant, temperature and concentration on the stability, thermal conductivity and viscosity of $\mathrm{Al}_{2} \mathrm{O}_{3}$ nanofluids. The effect of variation in temperature on nanofluid thermal conductivity and viscosity are very less reported and these properties are mainly useful directly to design elements or equipment. In general, thermal conductivity of fluid is measured by transient hot wire (THW) method. Here, we report alternative method for measuring thermal conductivity from the sound velocity by nanofluid interferometer method. Up to now, there is no reported work performed along with the combination of PVA capped alumina nanoparticles, which show the smaller size distribution and more stability in base fluid, which are crucial parameters for a nanofliud to be optimized. In recent work, we have used two-step nanofluid synthesis process. Therefore, we synthesized and characterized nanoparticles with PVA surfactant capped and without surfactant [particles are suspended in base fluid DW:EG (60:40) ratio]. Aluminum oxide nanoparticles are synthesized by sol-gel method. The characterization is done by scanning electron microscope (SEM), X-ray powder diffraction (XRD), UV-Visible spectroscopy and Fourier transform infrared spectroscopy (FTIR). The particle size is controlled by employing polyvinyl alcohol (PVA) surfactant which is synthetic polymer $\left[\mathrm{CH}_{2} \mathrm{CH}(\mathrm{OH})\right]_{n}$ and soluble in water (Agarwal et al. 2017). The work also investigates the effect of PVA additions on morphology of the alumina nanoparticles. The surface chemical treatment can change the suspension stability through surface charge states and resultant surface potential. The impacts of the surfactant (PVA) on particle size and the weight fraction of the dispersed alumina particles improved thermal conductivity proportion, which have been explored in our work. The contents of the paperare as below: the synthesis of alumina nanoparticles is reported in "Synthesis" then understanding of characterization parameters of synthesized particles is mentioned in "Characterization". The "Preparation of nanofluids" mentioned preparation of nanofluid, stability of nanofluid; thermal conductivity measurement technique then measured enhanced thermal conductivity with comparisons of previously reported works and effective viscosity with respect to temperature. While these transport properties are important for heat transfer applications. The viscosity is also important in designing nanofluids for flow and heat transfer applications because the pressure drop and the resulting pumping power depend on the viscosity. At last we conclude our reported results with key terms.

\section{Synthesis and characterizations of nanoparticles}

\section{Synthesis}

To synthesize $\alpha-\mathrm{Al}_{2} \mathrm{O}_{3}$ nanoparticles, we have used sol-gel method which is very advantageous for high purity and uniform nanostructure achievable at high temperatures. The inorganic aluminum chloride $\left(\mathrm{AlCl}_{3}\right)$ is utilized as a precursor, which is diluted in hot distilled water (DW) for all two synthesis process.

1. The $\mathrm{AlCl}_{3}$ is used as a precursor and the sol-gel synthesis consisted in the preparation of a $0.1 \mathrm{M} \mathrm{AlCl}_{3}$ diluted in DW by stirring process. By adding a $28 \%$ $\mathrm{NH}_{3}$ dropwise in the solution a gel was formed while no surfactant is added in this process.

2. In the second synthesis process PVA surfactant is added to the suspension. In this synthesis process $0.1 \mathrm{M} \mathrm{AlCl}_{3}$ is diluted in DW by magnetic stirrer. The same solution is also made with $0.5 \mathrm{M}$ PVA and added to the $\mathrm{AlCl}_{3}$ solutions while stirring. After that $28 \%$ $\mathrm{NH}_{3}$ was added dropwise in the solution and the gel started to form.

The gel was allowed to maturate with mother liquor for $24 \mathrm{~h}$ at room temperature and then dried at $100^{\circ} \mathrm{C}$ for $24 \mathrm{~h}$. The resulting gels were calcined in a furnace for $2 \mathrm{~h}$ (heating rate $20{ }^{\circ} \mathrm{C} / \mathrm{min}$ ), at temperature values of $800{ }^{\circ} \mathrm{C}$ and $1200{ }^{\circ} \mathrm{C}$. 


\section{Characterization}

\section{Scanning electron microscopy}

Morphological characterization of synthesised powder samples were observed by scanning electron microscopy analysis (SEM). SEM images taken after calcined at $1200{ }^{\circ} \mathrm{C} / 2 \mathrm{~h}$ show different geometries shapes with agglomeration. The images of alumina powder obtained with and without surfactants are displayed in the Fig. 1. SEM images are shown in two different magnifications. Figure 1a, $\mathrm{c}$ shows morphology at low magnification. Figure 1a shows bigger size particle formation while Fig. 1c,clearly shows agglomerated particles. In the high-resolution images of Fig. 1b, though particles are not clearly resolved due to charging effect in SEM, still bigger size agglomerated particles seem to be appear, while Fig. 1d shows agglomeration of smaller particles. Figure 1c, d also indicates that surfactant shows less agglomeration.

\section{$X$-ray diffraction}

$\mathrm{X}$-ray diffraction pattern is a basic method to explain the crystal structure of the synthesized nanoparticles, which has monochromatic $\mathrm{CuK}_{\alpha}$ radiations $(\lambda=0.15418 \mathrm{~nm})$, which is utilized as a source of energy $40 \mathrm{kV} / 35 \mathrm{~mA}$. And the graph is recorded in the range of $20^{\circ}-80^{\circ} 2 \theta$. The crystallite size of nanoparticles is shown in Table 1, which is calculated from the full width at half maximum [FWHM $(\beta)]$ of the diffraction peaks using Debye-Scherer's method (Cullity 1956) using the following equation:

$D=\frac{0.89 \lambda}{\beta \cos \theta}$

where ' $D$ ' is the average crystalline dimension perpendicular to the surface of the specimen, ' $\lambda$ ' is the wavelength of used X-ray, ' $k$ ' is Scherer's constant (0.89), ' $\beta$ ' is the full width at half maximum (FWHM) intensity of a Bragg reflection excluding instrumental broadening, and ' $\theta$ ' is the Bragg's angle. This Scherer's equation is derived based on the assumption of Gaussian lines. The calculated average crystallite size of the product is shown in Table 1.

Figure 2 shows $\mathrm{X}$-ray diffraction for the nanoparticles which are synthesized by $\mathrm{AlCl}_{3}$ precursors for different calcination temperatures at $800{ }^{\circ} \mathrm{C} / 2 \mathrm{~h}$ (red color) and $1200{ }^{\circ} \mathrm{C} / 2 \mathrm{~h}$ (blue color) and shows a diffuse peak between $20^{\circ}$ and $80^{\circ}(2 \theta)$. Both the samples with and without surfactants are calcinated till $800{ }^{\circ} \mathrm{C}$, indicating amorphous

\section{Sample-1}
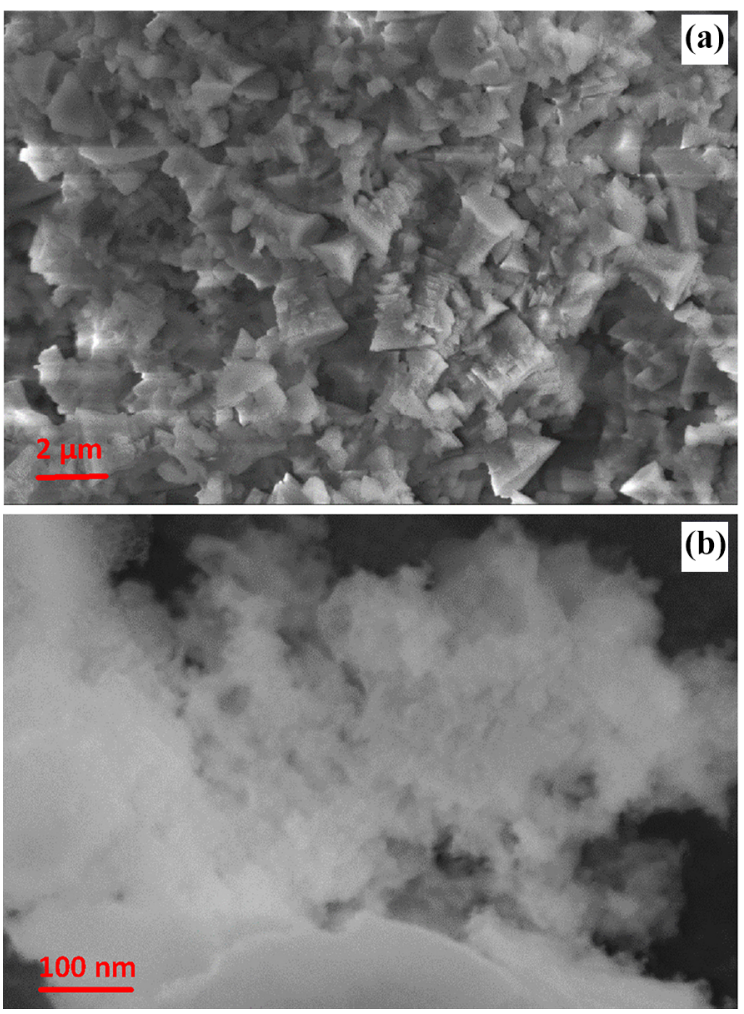

\section{Sample-2}
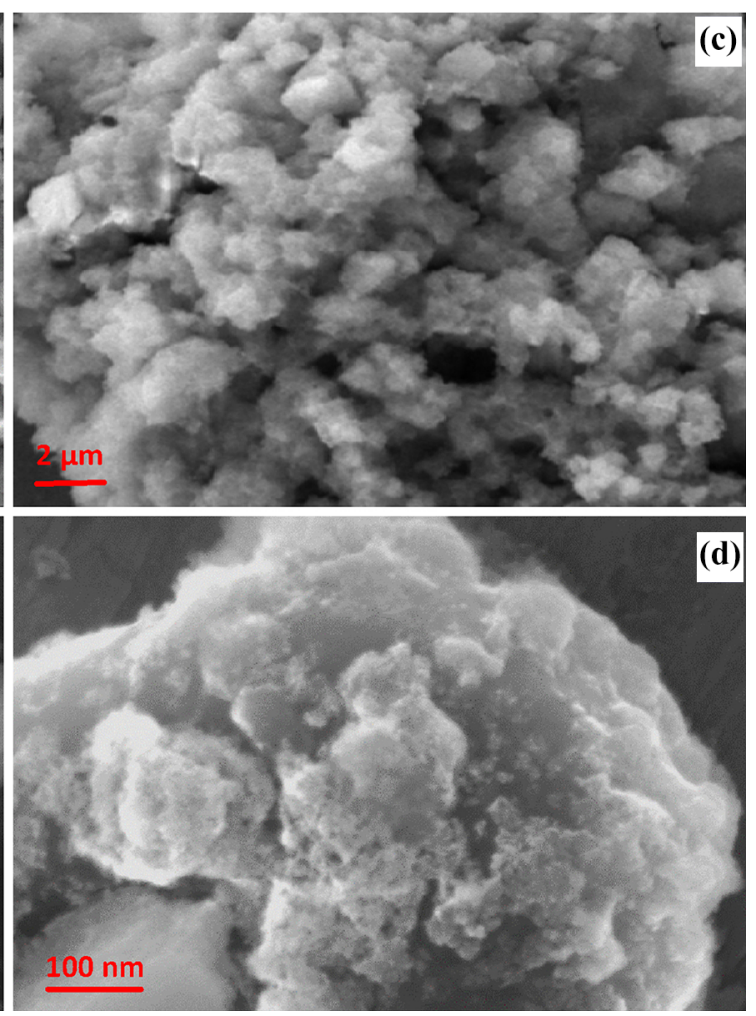

Fig. 1 Observed SEM images of synthesised alumina by sol-gel method calcined at $1200{ }^{\circ} \mathrm{C} / 2 \mathrm{~h}$. Sample 1 is for without surfactant and sample 2 for with PVA surfactant with different magnification 
Table 1 The average crystalline sizes of $\alpha-\mathrm{Al}_{2} \mathrm{O}_{3}$ (with and without surfactant) and calculated bandgap

\begin{tabular}{llllll}
\hline No. & Salt + solvent & Surfactant & Sample & Crystalline size $(\mathrm{nm})$ & Bandgap $(\mathrm{eV})$ \\
\hline 1 & $\mathrm{AlCl}_{3}+\mathrm{Hot}$ DW & - & $\alpha-\mathrm{Al}_{2} \mathrm{O}_{3}$ & 36 & 4.42 \\
2 & $\mathrm{AlCl}_{3}+\mathrm{Hot}$ DW & PVA & $\alpha-\mathrm{Al}_{2} \mathrm{O}_{3}$ & 23 & 4.59 \\
\hline
\end{tabular}

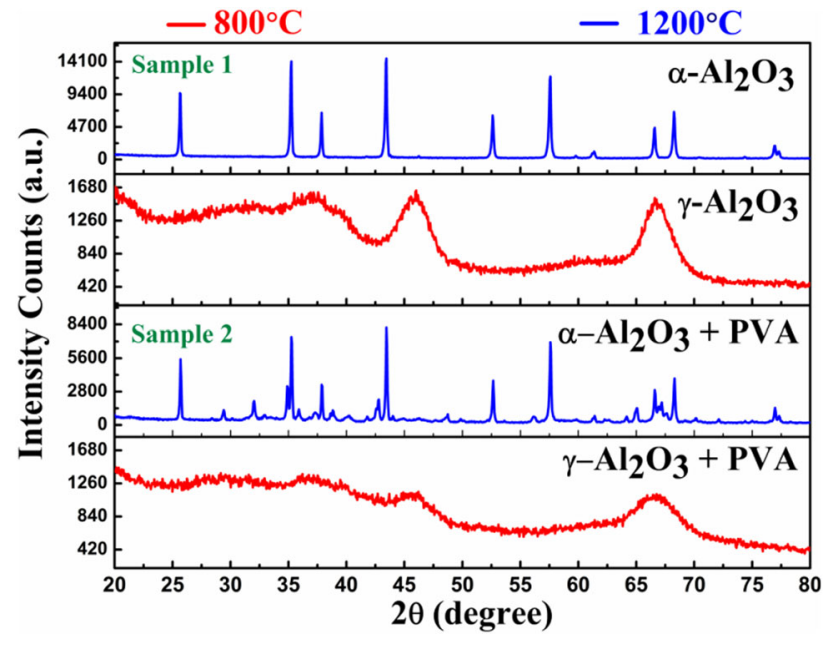

Fig. 2 The XRD pattern of alumina powder obtained by sol-gel method from aluminum chloride $\left(\mathrm{AlCl}_{3}\right)$ without surfactant (sample 1) and with surfactant PVA (sample 2) where red color indicates calcination at $800{ }^{\circ} \mathrm{C} / 2 \mathrm{~h}$ which is $\gamma-\mathrm{Al}_{2} \mathrm{O}_{3}$ and blue color shows calcination at $1200{ }^{\circ} \mathrm{C} / 2 \mathrm{~h}$ which is $\alpha-\mathrm{Al}_{2} \mathrm{O}_{3}$

phase of alumina. These diffraction peaks in XRD pattern show index regarding $\gamma-\mathrm{Al}_{2} \mathrm{O}_{3}$, which matches with JCPDS Card no. 29-0063 (Wallin et al. 2008) and still some amorphous phase is present in this sample during transformation. Thereafter, heating at $800{ }^{\circ} \mathrm{C}$ for $2 \mathrm{~h}$ leads to decomposition with the formation of $\gamma-\mathrm{Al}_{2} \mathrm{O}_{3}$ phase (Card no. 29-0063) (Wallin et al. 2008). While increasing temperature up to $1200{ }^{\circ} \mathrm{C}$ for $2 \mathrm{~h}$, the phase transformation started to take place, $\alpha-\mathrm{Al}_{2} \mathrm{O}_{3}$ phase (JCPDS no. 46-1212). The peaks that appeared at $2 \theta$ values of $25.71^{\circ}, 35.18^{\circ}$, $38.90^{\circ}, 43.44^{\circ}, 52.67^{\circ}, 57.58^{\circ}, 60.41^{\circ}, 66.57^{\circ}, 68.24^{\circ}$, and $77.01^{\circ}$ correspond to the (012), (104), (110), (113), (024), (116), (018), (214), (300), and (119) lattice planes of $\mathrm{Al}_{2} \mathrm{O}_{3}$, respectively (Pathania et al. 2016). The calcined temperature is rising till $1200{ }^{\circ} \mathrm{C}$, then $\gamma-\mathrm{Al}_{2} \mathrm{O}_{3}$ phase mostly transformed into $\alpha-\mathrm{Al}_{2} \mathrm{O}_{3}$ crystalline stable phase. This crystalline phase is obtained because of interface migration from $\alpha-\mathrm{Al}_{2} \mathrm{O}_{3}$ nuclei or by the coalescence among the $\alpha-\mathrm{Al}_{2} \mathrm{O}_{3}$ nuclei. Therefore, at high transformation temperature, particles are coarsening and formation of hard agglomerates in the powder.

While giving more annealing temperature, phase transformation $\gamma-\mathrm{Al}_{2} \mathrm{O}_{3} \rightarrow \alpha-\mathrm{Al}_{2} \mathrm{O}_{3}$ takes place with highly reactive ultra-fine $\alpha$ alumina powder, which shows highly intense peak with full width half maxima (FWHM). For sample 1, the calculated average crystalline diameter is 36 $\mathrm{nm}$ for without surfactant. But when surfactant is added during synthesis process, the surface energy of the particles is modulated by surfactant. So that decreases the surface tension thus allowing more particles to ignore aggregation process and generally lowering the mean particle size. Hence, with PVA surfactant (sample 2) average crystalline size is $23 \mathrm{~nm}$ which is the best result compared to previous results with different additives also (Sathyaseelan et al. 2013).

\section{UV-Visible analysis}

The variation of absorption process in $\alpha-\mathrm{Al}_{2} \mathrm{O}_{3}$ nanoparticles with and without surfactant as a function of wavelength is shown in Fig. 3. The strong adsorption peaks were obtained between 200 to $400 \mathrm{~nm}$ which confirms the presence of $\alpha-\mathrm{Al}_{2} \mathrm{O}_{3}$ nanoparticles. It is also clear that without surfactant absorbance is occurring at $280 \mathrm{~nm}$ and with PVA surfactant $270 \mathrm{~nm}$ which shows agreement with the result of previous work (Neethumol et al. 2014). The

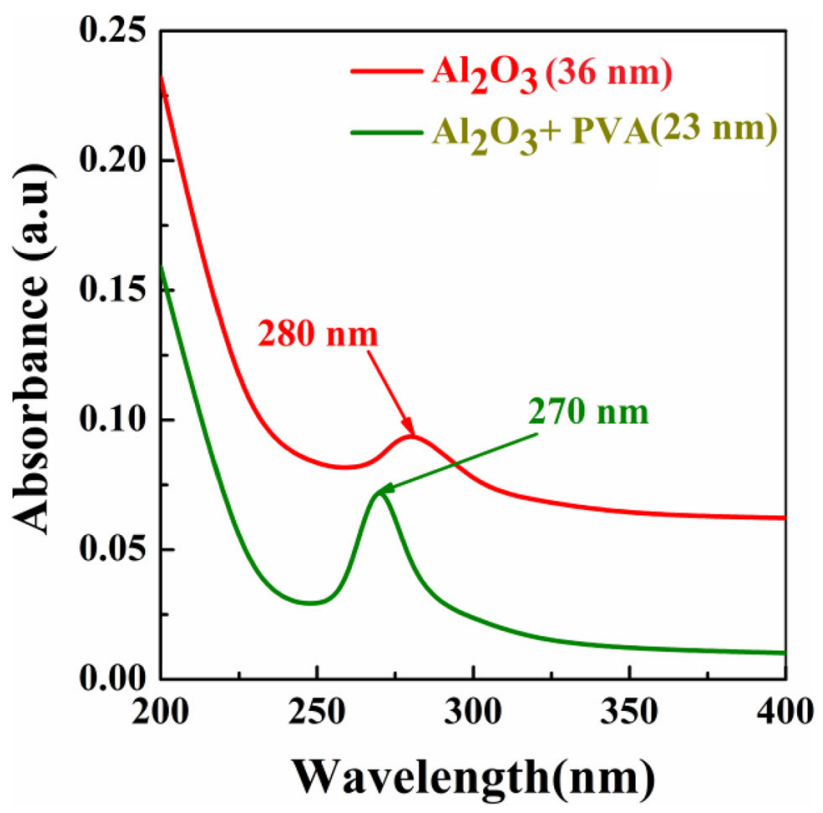

Fig. 3 UV-Visible spectra of $\alpha-\mathrm{Al}_{2} \mathrm{O}_{3}$ with and without surfactant 
bandgap is also calculated from UV-Visible spectra using Eq. (2):

$E=\frac{h c}{\lambda}$

In above equation, $E$ denotes band gap energy, $c$ is for velocity of light, $h$ valued for Planck's constant, and $\lambda$ noted as wavelength of absorption edge in reflectance spectra. The bandgap energy of alumina nanoparticles without surfactant shows bandgap $4.42 \mathrm{eV}$ and PVA capped alumina nanoparticles have $4.59 \mathrm{eV}$, respectively, as shown in Table 1. Here, we can conclude that surfactant capped alumina nanoparticles have more bandgap compared to without surfactant alumina. The bandgap increases in band gap energy revealed the decrease in particle size with addition of PVA. Our reported results show good agreement with previous reported work (Malviya et al.2013).

\section{Fourier transform infrared spectra}

A Fourier transform infrared spectra (FTIR) are performed here to analyse alumina nanoparticles in the absence or presence of surfactant in the region of wave numbers $500-4000 \mathrm{~cm}^{-1}$ (Fig. 4).

An intense, strong, and broad peak of alumina nanoparticles without surfactant and with PVA surfactant observed around $3300 \mathrm{~cm}^{-1}$ and the other peak is around $950 \mathrm{~cm}^{-1}$ which denotes $\mathrm{O}-\mathrm{H}$ stretching and showing bending modes for water or alcohol group, respectively (Neethumol et al. 2014). Here, the noticeable difference between the alumina nanoparticles without surfactant and with PVA surfactant was due to the $\mathrm{Al}-\mathrm{O}$ bond appearing between 500 to $950 \mathrm{~cm}^{-1}$.

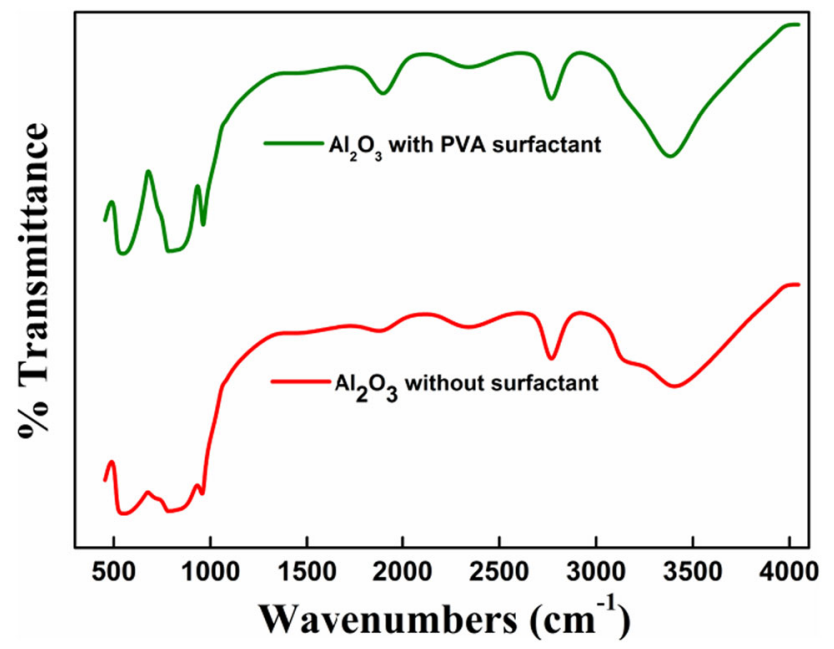

Fig. 4 The FTIR spectra of $\alpha-\mathrm{Al}_{2} \mathrm{O}_{3}$ nanoparticles without surfactant (red color) and with PVA surfactant (green color), respectively potted
The main peak is observed around $750 \mathrm{~cm}^{-1}$ and another peak $950 \mathrm{~cm}^{-1}$ is much sharper than without surfactant graph, which confirms that PVA surfactant is presented in some matrix (Darban et al. 2013; Juneja and Gangacharyulu 2013).

\section{Preparation of nanofluids}

Nanofluid is prepared by two types of process like singlestep and two-step methods. In single-step method nanoparticles are synthesized and dispersed simultaneously with same time in base fluid whereas, two-step method nanoparticles and nanofluid dispersion process is separated. Wang et al. (2007) and Zhu et al. (2004) concluded that a single-step method is usually used for metal nanofluid preparation and for combining process for nanoparticles and nanofluid synthesis are done with the help of physical vapor deposition (PVD) method or a liquid chemical method. While two-step synthesis process is mainly used for oxide nanoparticles contains nanofluid to prevent agglomeration. In this method, dry nanoparticles are synthesized first by any chemical or physical method and then dispersed in base fluid with certain concentration. When, nanoparticles have higher surface energy because of larger surface area, where agglomeration and clustering are unavoidable. The particles agglomerate due to the large surface area and higher concentration of particles and settle down at the bottom of the fluid. Thus, preparing a homogeneous stable suspension by two-step method is slightly difficult (Shah et al. 2017).

Here, in our work we prepare $\mathrm{Al}_{2} \mathrm{O}_{3}$ nanofluid by twostep method, having $\mathrm{Al}_{2} \mathrm{O}_{3}$ nanoparticles of $36 \mathrm{~nm}$ without additives and $23 \mathrm{~nm}$ with PVA surfactant by sol-gel method and then dispersed in base fluid. This base fluid is mixture of DW and EG with the ratio of $60: 40$ by ultrasonication.

$\phi=\frac{\left(\frac{W_{\mathrm{p}}}{\rho_{\mathrm{p}}}\right)}{\left(\frac{W_{\mathrm{p}}}{\rho_{\mathrm{p}}}+\frac{W_{\mathrm{bf}}}{\rho_{\mathrm{bf}}}\right)} \times 100 \%$

Equation (3) calculates the amount of nanoparticles to disperse into base fluid as a function of concentration (Senthilraja et al. 2015), where $\phi$ is the percentage of concentration, $W_{\mathrm{p}}$ is weight of $\mathrm{Al}_{2} \mathrm{O}_{3}$ particles, $\rho_{\mathrm{p}}$ is the density of $\mathrm{Al}_{2} \mathrm{O}_{3}=3970 \mathrm{~kg} / \mathrm{m}^{3}, W_{\mathrm{bf}}$ is the weight of base fluid and $\rho_{\mathrm{bf}}$ is the density of base fluid mixture. Here we prepare 0.1 and $0.5 \mathrm{wt} \%$ concentrations of synthesized alumina nanoparticles with and without additives in mixture of water + ethylene glycol base fluid. To maintain stability of nanoparticles in base fluid, the solution is mixed with magnetic stirring for $2 \mathrm{~h}$. For better suspension ultra-sonication is also done for $2 \mathrm{~h}$. The 
ultrasonic vibration helps to break down agglomerations in the suspension. This nanofluid has been observed for 15 days to check stability.

Figure 5 shows well dispersed suspended particles with $0.1 \mathrm{wt} \%$ as well as $0.5 \mathrm{wt} \%$ for with and without PVA surfactant. The addition of surfactants is an important key to enhance the stability of nanofluids. The suspension with PVP surfactant which is non-ionic shows better dispersion and better stability than without surfactant fluid.

\section{Stability of nanofluid}

Addition of surfactants in mother liquor reduces the surface tension and increases particle immersion. The previous works concluded that adding surfactant to nanofluids avoids fast sedimentation (Mishra et al. 2013). The stability of nanofluid can be enhanced by adding suitable surfactant or by ultra-sonication or by $\mathrm{pH}$ controlling. The zeta potential range for stability of fluid is distributed as below $\pm 30 \mathrm{mV}$ shows limited stability, $\pm 30 \mathrm{mV}$ to $\pm 40 \mathrm{mV}$ is physically stable and above $\pm 45 \mathrm{mV}$ show excellent stability (Sundar et al. 2014). While below $\pm 15 \mathrm{mV}$ undergoes marked aggregation (Timofeeva et al. 2007).

Here we analyzed zeta potential of dilute of $\alpha-\mathrm{Al}_{2} \mathrm{O}_{3}$ nanoparticles in DW: EG (60:40) suspension as low as 0.1 $\mathrm{wt} \%$ and $0.5 \mathrm{wt} \%$. These fluids are sonicated for $2 \mathrm{~h}$ and then analyse for with and without PVA surfactant at room temperature. Figure 6 shows nanofluid suspension with surfactant nanofluid which is more stable and negative value indicates negative charge distribution on surface. Uniform and stable suspension of nanoparticles in base fluid is the main characteristic for most applications of nanofluids. So here fluid shows moderate stability for with surfactant capped particles and very good stability with

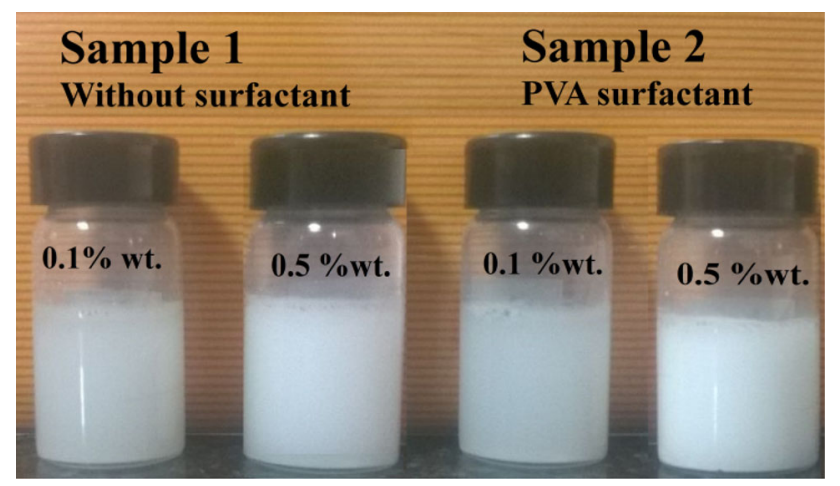

Fig. 5 Alumina nanofluid after 15 days of preparation with 0.1 and $0.5 \mathrm{wt} \%$ concentration which is suspended in water: ethylene glycol (60:40). Sample 1 is for without surfactant and sample 2 for with PVA surfactant

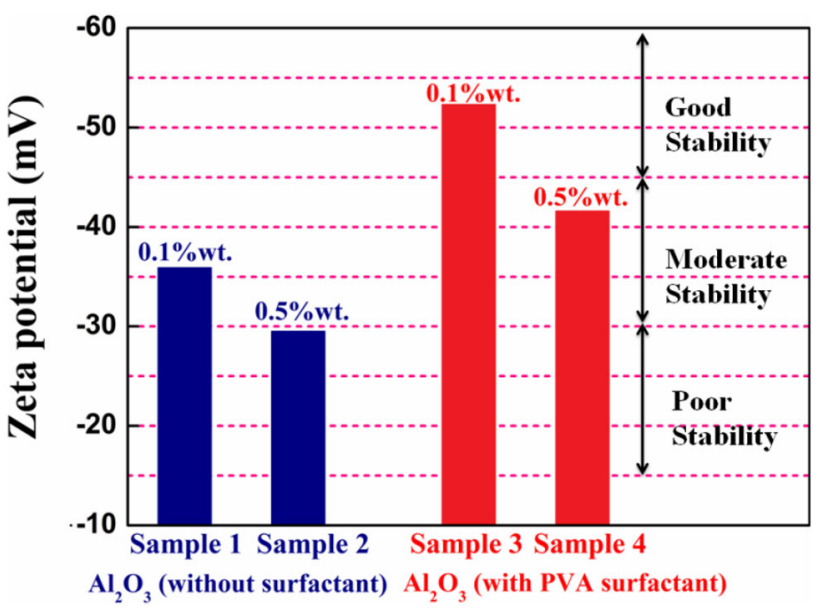

Fig. 6 Zeta potential analysis for $\alpha-\mathrm{Al}_{2} \mathrm{O}_{3}$ nanoparticles suspended in DW:EG (60:40) mixture base fluid with and without PVA surfactant with different concentrations

PVA capped suspended particles with respect to concentration (Sundar et al. 2013a, b).

\section{Measurement setup of nanofluid interferometer}

Here, the thermal conductivity of $\mathrm{Al}_{2} \mathrm{O}_{3}$ /water: EG nanofluids is found out experimentally from sound velocity with the help of nanofluid interferometer instruments.

The principle of nanofluid interferometer is to measure the sound velocity $\left(v_{\mathrm{s}}\right)$ of fluid which is relying on the accurate determination of presentation length $(\lambda)$ in the present medium. Ultrasonic waves of known frequency $(f)$ are created by a quartz plate which is settled at the base of the cell of interferometer (Saxena et al. 2013). Temperature Controller Unit is helpful to maintain temperature of nanofluids at desired temperature from 25 to $90{ }^{\circ} \mathrm{C}$. The sound velocity in nanofluids is $v_{\mathrm{s}}=\lambda f$.

We measure sound velocity of 0.1 and $0.5 \mathrm{wt} \%$ concentrated alumina in 60:40 ratio of water: ethylene glycol for with and without PVA surfactant. It can be observed from the Fig. 7 that DW + EG mixture has low sound velocity compared to alumina added nanofluid. It is also shown that non added surfactant sound velocity is less compared with PVA additives due to that larger molecules (without surfactant) have more mass and they will transmit sound slower. Sound waves are comprised from the kinetic energy. In this manner, sound will travel at a slower rate in the dense object for a similar medium. The graph shows that $0.1 \mathrm{wt} \%$ concentrated fluid gives low sound velocity compared with $0.5 \mathrm{wt} \%$ concentration with respect to temperature. Therefore, we can conclude that with surfactant and concentration, the sound velocity increases with respect to temperature. 
Fig. 7 Measured sound velocity of DW + EG (60:40) and alumina nanofluid with 0.1 and $0.5 \mathrm{wt} \%$ concentration in mixture of base fluid that corresponds to temperature $30-80{ }^{\circ} \mathrm{C}$

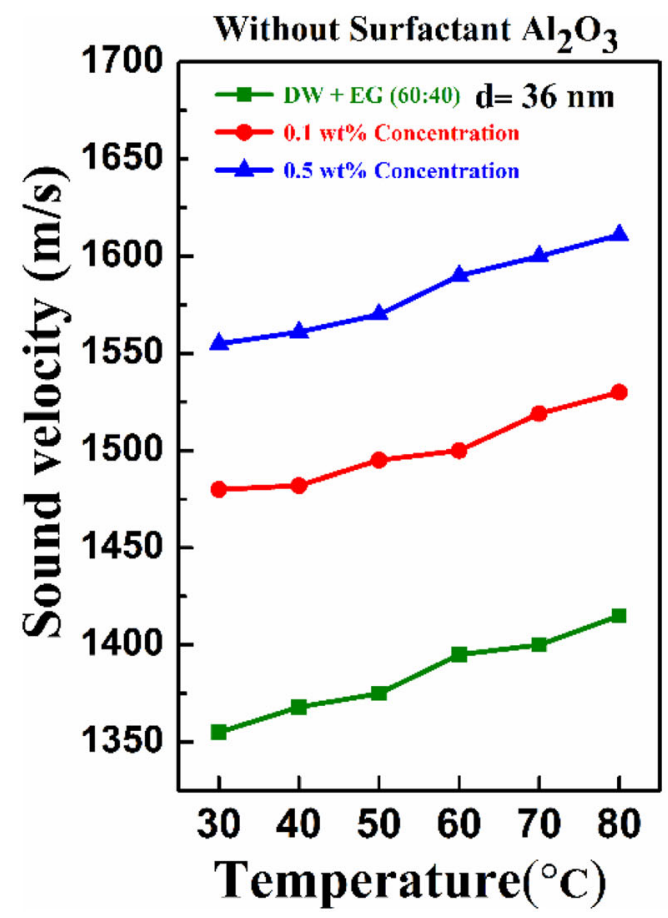

\section{Thermal conductivity of nanofluid}

Depending upon heat transfer mechanism, Bridgman acquired a formula in 1923, which predicts direct proportionality of the thermal conductivity and sound velocity in pure liquid (Lin and Pate 1992). Here, thermal conductivity is calculated from sound velocity by following Bridgman's modified equation:

$k_{\mathrm{b}}=3\left(\frac{N}{V}\right)^{\frac{2}{3}} K_{\mathrm{B}} v_{\mathrm{S}}$

$V=\frac{M_{\mathrm{nf}}}{\rho}$

$M_{\mathrm{nf}}=\chi_{\mathrm{bf}} M_{\mathrm{bf}}+\chi_{\mathrm{p}} M_{\mathrm{p}}$,

Where $k_{\mathrm{b}}$ is the thermal conductivity obtained by the modified Bridgman equation, $v_{\mathrm{s}}$ is the ultrasound velocity, $N$ is the Avogadro's number $=6.02 \times 10^{23}, V$ is the molar volume, $K_{\mathrm{B}}$ is the Boltzmann's constant $=1.3807 \times 10^{-23}$ $\mathrm{J} / \mathrm{K} . \rho_{\mathrm{nf}}$ defines the density of nanofluid, and $M_{\mathrm{nf}}$ is the molar mass of nanofluid. $\chi_{\mathrm{bf}}$ and $\chi_{\mathrm{p}}$ are the molar fractions of the base fluid and nanoparticles, respectively. Here, $M_{\mathrm{bf}}$ and $M_{\mathrm{p}}$ are molar masses of the base fluid and nanoparticles, respectively. Here, we pour nanofluid of 0.1 and $0.5 \mathrm{wt} \%$ concentration of alumina into the base fluid of water and ethylene glycol and sound velocity is generated. Using above equations we calculate thermal conductivity of nanofluid with increasing temperature from 30 to $80{ }^{\circ} \mathrm{C}$.

Figure 8 displays the change in the thermal conductivity ratio for nanofluid where alumina nanoparticles are suspended in DW:EG mixture with a ratio of $60: 40$, where results vary with concentration correspond to a temperature range of $30-80{ }^{\circ} \mathrm{C}$. The average crystalline size is main term to enhance thermal conductivity, as crystalline size decreases thermal conductivity increases. The concentration and temperature both increase; then nanoparticles start to collide in fluid and quasi-convection phenomenon is taking place. The random collision increases and will help to enhance thermal conductivity.

Here, we can observe that without surfactant (left) thermal conductivity ratio is less than with PVA surfactant (right). With $0.1 \mathrm{wt} \%$ concentration thermal conductivity ratio for without surfactant is $1.25-1.27$ which varies with temperature range $30-80{ }^{\circ} \mathrm{C}$. As concentration increases 0.1 to $0.5 \%$ wt, thermal conductivity ratio also increases up to 1.46 with temperature $30-80{ }^{\circ} \mathrm{C}$. That shows that as concentration increases thermal conductivity also increases. The similar results are observed for PVA additives. Due to the temperature and concentration, thermal conductivity has been increased, but the main observation with surfactant thermal conductivity shows maximum enhancement with results. The added surfactant amount is most important in synthesis because more or less amount of additives affect thermal conductivity directly.

The addition of surfactant can be used to increase the thermal conductivity of nanofluid but it also depends on the concentration of particles. The excess amount of surfactant can interrupt enhancement of thermal conductivity but when the additive is insufficient, the surfactant molecule cannot be coated properly with the formed nanoparticles. 
Fig. 8 Measured thermal conductivity ratio of alumina nanofluid with 0.1 and $0.5 \mathrm{wt} \%$ concentration in water + ethylene glycol mixture base fluid that corresponds to temperature $30-80{ }^{\circ} \mathrm{C}$ without surfactant (left) and with PVA surfactant (right)

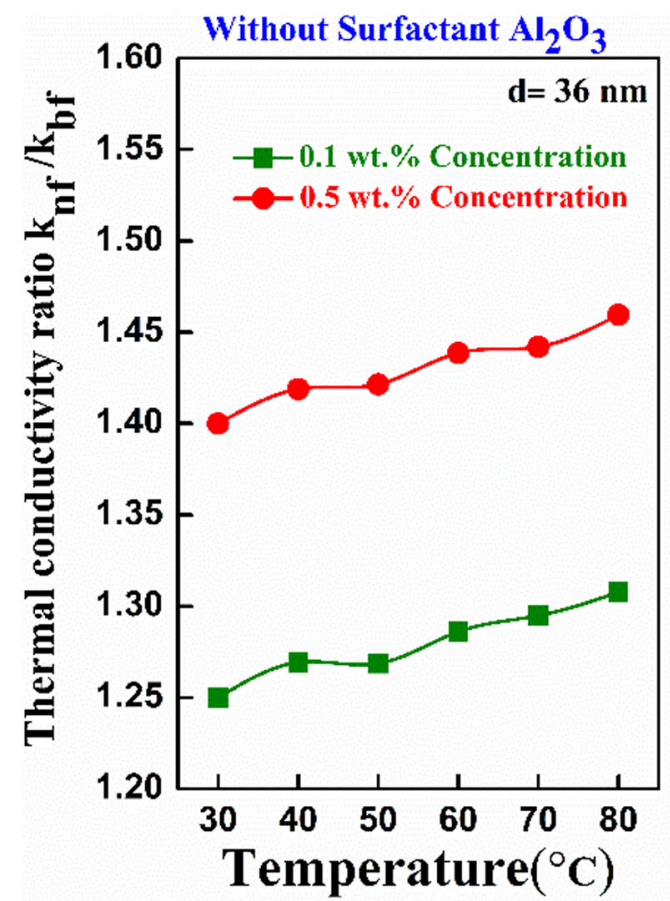

Due to this electrostatic repulsion decreasing between particles they started to agglomerate. As increasing more amount of surfctant, the dispersion is started to saturate and particles aggregates. They start to form clotting like masses or precipitate into small lumps and weaken the heat transfer between particles (Wang and Zhu 2009).

Here, we compare our results with previously reported work of various basic classical models for thermal conductivity of nanofluid. We are getting same type of increasing nature of thermal conductivity with respect to concentration and temperature. The thermal conductivity enhancement is also upgraded with the decreasing size of nanoparticle. Our stable suspension is reporting thermal conductivity enhancement compared to previous works shown in Fig. 9. The basic Maxwell (1954) model is useful in assuming the effective thermal and electrical conductivities of particles which are monodispersly suspended with low concentration of spherical shaped particles. Another classical model of thermal conductivity is given by Hamilton and Crosser (1962) which is an extension of Maxwell's theory of non-spherical particles. Basic classical models are mainly giving conclusions regarding particle size, shape, concentration, which helps to assume heat transfer in particles as well as in fluid (Wang et al. 2008). Beck et al. (2009) and Moghadassi et al. (2010) observed that the thermal conductivity will upgrade with the decreasing of nanoparticle size. Kleinstreuer and Feng (2011) established relationship between thermal conductivity and some fundamental parameters like concentration, temperature, particle size which are exceptionally valuable for a nanofluid. Chon et al. (2005) reported the inversely dependence of particle size on thermal conductivity upgrade, considering distinctive sizes of alumina nanoparticles suspended in water base fluid. Another basic model is given by $\mathrm{Li}$ and Peterson (2006) where they explain thermal conductivity expressions correspond to temperature and concentration by using curve fitting for $\mathrm{Al}_{2} \mathrm{O}_{3}$-water nanofluids.

\section{Effective viscosity of nanofluid}

Viscosity describes internal resistance of fluid in the flowing conditions and, nanofluids relies upon the morphology, size and shape of nanoparticles, additives and essentially concentration of suspended particles. Here, alumina nanofluids for effective viscosity were analyzed for 0.1 and $0.5 \mathrm{wt} \%$ concentrations with PVA surfactant and without surfactant fluid with respect to varying temperature range in $25-40{ }^{\circ} \mathrm{C}$ (Fig. 10). The results show that as concentrations of suspended particles increase the viscosity of fluid also increases. The viscosity of the nanofluids has been decreased with increasing temperature. The concentration of the alumina nanoparticles in the fluid is responsible for the increases in the viscosity due to increases the friction and flowing resistance of fluid. The density of nanofluid is decreased as the reduction of the shear stress and viscosity with respect to temperature (Lotfizadeh et al. 2013a, b). The effective viscosity of alumina nanofluids has been analyzed at 0.01-1 vol\% concentrations and temperature in the range of $25-40{ }^{\circ} \mathrm{C}$ 


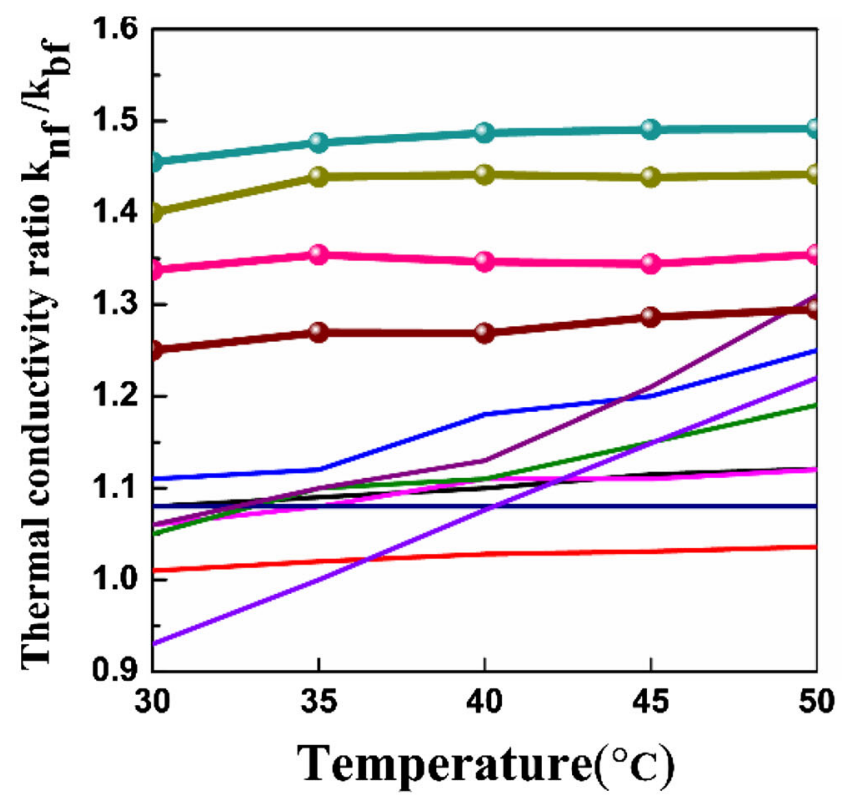

\section{Presented work}

$-0.5 \% \alpha-\mathrm{Al}_{2} \mathrm{O}_{3}+$ PVA -DW:EG(60:40),d=23nm

$-0.1 \% \alpha-\mathrm{Al}_{2} \mathrm{O}_{3}+\mathrm{PVA}-\mathrm{DW}: \mathrm{EG}(60: 40), \mathrm{d}=23 \mathrm{~nm}$

$-0.5 \% \alpha-\mathrm{Al}_{2} \mathrm{O}_{3}$ - DW:EG(60:40),d=36nm

$\longrightarrow 0.1 \% \alpha-\mathrm{Al}_{2} \mathrm{O}_{3}-\mathrm{DW}: \mathrm{EG}(60: 40), \mathrm{d}=36 \mathrm{~nm}$

\section{Reported models}

- Beck et al. $\mathrm{Al}_{2} \mathrm{O}_{3}$-Water, $\mathrm{d}=12 \mathrm{~nm}, 1 \%$ wt (2010)

- Beck et al. $\mathrm{Al}_{2} \mathrm{O}_{3}-\mathrm{EG}, \mathrm{d}=12 \mathrm{~nm}, 1 \% \mathrm{wt}$ (2010)

- Jung et al. $\mathrm{Al}_{2} \mathrm{O}_{3}-$ Water, $\mathrm{d}=47 \mathrm{~nm}, 1 \% \mathrm{wt}$ (2009)

Chen et al. $\mathrm{Al}_{2} \mathrm{O}_{3}$-Water, $\mathrm{d}=47 \mathrm{~nm}, 1 \% \mathrm{wt}$ (2005)

-Mintsa et al. $\mathrm{Al}_{2} \mathrm{O}_{3}$-Water, $\mathrm{d}=36 \mathrm{~nm}$ (2009)

- Hamilton \& Crosser, $d=36 \mathrm{~nm}(1962)$

Li \& Peterson, $d=36 \mathrm{~nm}$ (2006)

\section{0}

Chon et al., $d=36 n m(2005)$

Fig. 9 Comparison with previously reported work and our proposed

Wang et al. 2008; Beck et al. 2009; Moghadassi et al. 2010; work on temperature-dependent nanofluid thermal conductivity ratio for alumina nanofluid (Maxwell 1954; Hamilton and Crosser 1962;

Kleinstreuer and Feng 2011; Chon et al. 2005; Li and Peterson 2006)

Fig. 10 Measured viscosity of alumina nanofluid with 0.1 and $0.5 \mathrm{wt} \%$ concentration in water + ethylene glycol mixture base fluid that corresponds to temperature $25-40{ }^{\circ} \mathrm{C}$ without surfactant (left) and with PVA surfactant (right)

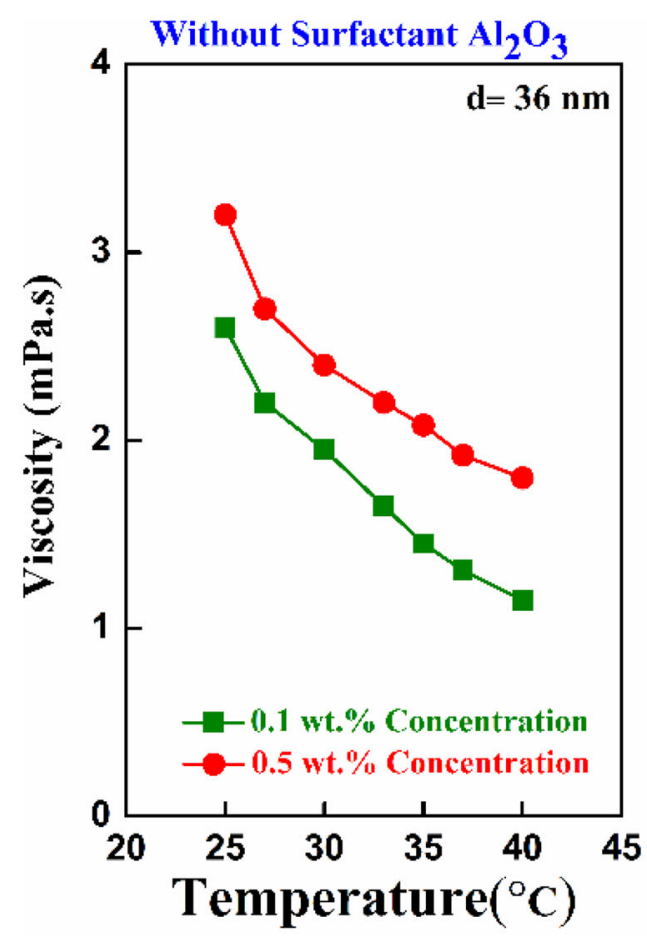

by the ASHRAE standard data (ASHRAE 2001). Therefore, the decreasing the density of the nanofluids is responsible for the reduction of shear stress, same as the previous experimental reported prediction.

Here we compare viscosity of alumina nanofluid with reference data reported by Incropera and Dewitt (2002). They predict the effective viscosity of $\mathrm{Al}_{2} \mathrm{O}_{3}$ nanofluids with low concentrations from 0.1 to 0.3 wt\% with temperature range from 21 to $39^{\circ} \mathrm{C}$. The effective viscosity of nanofluids expressively decreases with increasing temperature and increases with higher volume fraction. The results also show good agreement with theoretical predictions of the Einstein model of the effective viscosity of dilute suspensions (Lee et al. 2008). 
Due to the particle volume concentration the dynamic viscosity of nanofluid has been increased and as temperature increases viscosity decreases, which is concluded by Nguyen et al. (Nguyen et al. 2008; Chandrasekar et al. 2010). This process is the witness for the particle suspension beyond the critical temperature, which caused by the hysteresis phenomenon.

\section{Conclusions}

Alumina nanoparticles are synthesized by chemical sol-gel method for with and without PVA surfactant suspended in DW:EG (60:40) base fluid with 0.1 and $0.5 \mathrm{wt} \%$ concentration. This method has potential to scale up large amount of nanofluid via direct route of synthesis metal oxide nanoparticle. These synthesized nanoparticles are characterized by SEM, XRD, UV-Visible and FTIR. It is clearly visualized from SEM images that added surfactant nanoparticles get less agglomeration compared to without surfactant. The XRD revealed that at $800{ }^{\circ} \mathrm{C}$ alumina shows gamma phase, while at higher annealing temperature $1200{ }^{\circ} \mathrm{C}$ phase transformation takes place from $\gamma-\mathrm{Al}_{2} \mathrm{O}_{3}$ to $\alpha-\mathrm{Al}_{2} \mathrm{O}_{3}$ nanoparticles were good in crystalline nature and had more stable corundum phase. The calculated average crystalline size of particles using the Debye-Scherrer formula and calculated crystalline size is $36 \mathrm{~nm}$ for without surfactant and $23 \mathrm{~nm}$ for with PVA surfactant. UV-Visible absorption peak is denoted at $280 \mathrm{~nm}$ for without surfactant and $270 \mathrm{~nm}$ for with PVA capped nanoparticles which show bandgap of 4.42 and $4.59 \mathrm{eV}$, respectively. The particle size is decreasing while adding surfactant and hence bandgap increases. The FTIR analysis gave information regarding present group in material and added surfactant functional group. We have calculated thermal conductivity ratio by using Bridgman's equation. It is observed that thermal conductivity ratio increases as nanoparticle crystalline size decreases corresponding to increasing temperature. As well as thermal conductivity ratio also increases as volume concentration and temperature increase. However, the nanofluid viscosity decreased exponentially with the increase of temperature. At certain equilibrium concentration of suspended particles, the surfactant is helpful to stabilize nanofluid for enhancing thermal conductivity. The reported $\alpha$-alumina nanofluids with enhanced thermal properties can be used in power generation, automotive, transportation, electronic cooling and newer microchannel heat sink.

Open Access This article is distributed under the terms of the Creative Commons Attribution 4.0 International License (http:// creativecommons.org/licenses/by/4.0/), which permits unrestricted use, distribution, and reproduction in any medium, provided you give appropriate credit to the original author(s) and the source, provide a link to the Creative Commons license, and indicate if changes were made.

\section{References}

Agarwal R, Verma K, Agrawal NK, Singh R (2017) Sensitivity of thermal conductivity for $\mathrm{Al}_{2} \mathrm{O}_{3}$ nanofluids. Exp Therm Fluid Sci 80:19-26

Akbar NS, Butt AW (2015) Ferromagnetic effects for peristaltic flow of $\mathrm{Cu}$-water nanofluid for different shapes of nanosize particles. Appl Nanosci 6(3):379

Amirshaghaghi A, Kokabi $\mathrm{M}$ (2010) Tailoring size of $\alpha-\mathrm{Al}_{2} \mathrm{O}_{3}$ nanopowders via polymeric gel-net method. Iran Polym J 19(8):615-624

ASHRAE (2001) ASHRAE Handbook, Fundamentals 2001. American Society of Heating, Refrigerating and Air-Conditioning Engineers Inc, Atlanta

Beck MP, Yuan Y, Warrier P, Teja AS (2009) The effect of particle size on the thermal conductivity of alumina nanofluids. J Nanopart Res 11:1129-1136

Chandrasekar M, Suresh S, Bose AC (2010) Experimental investigations and theoretical determination of thermal conductivity and viscosity of $\mathrm{Al}_{2} \mathrm{O}_{3} /$ water nanofluid. Exp Therm Fluid Sci 34(2):210-216

Chon CH, Kihm KD, Lee SP, Choi SUS (2005) Empirical correlation finding the role of temperature and particle size for nanofluid $\left(\mathrm{Al}_{2} \mathrm{O}_{3}\right)$ thermal conductivity enhancement. Appl Phys Lett 87:153107

Cullity BD (1956) Elements of X ray diffraction. Addison-Wesley Publishing Company Inc, Reading, p 531

Darban AK, Kianinia Y, Taheri-Nassaj E (2013) Synthesis of nanoalumina powder from impure kaolin and its application for arsenite removal from aqueous solutions. J Environ Health Sci Eng 11:19

Eastman JA, Choi US, Li S, Thompson LJ, Lee S (1996) Enhanced thermal conductivity through the development of nanofluids. MRS Online Proc Libr Arch 457:3

Hamilton RL, Crosser OK (1962) Thermal conductivity of heterogeneous two component systems. Ind Eng Chem Fundam 1(3):187-191

Han Z (2008) Nanofluids with enhanced thermal transport properties (Doctoral dissertation)

Incropera FP, Dewitt DP (2002) Fundamentals of heat and mass transfer, 5th edn. Wiley, New York

Jang SP, Choi SU (2006) Cooling performance of a microchannel heat sink with nanofluids. Appl Therm Eng 26(17):2457-2463

Juneja M, Gangacharyulu D (2013) Experimental analysis on influence of temperature and volume fraction of nanofluids on thermophysical properties. Int J Emerg Technol Comput Appl Sci 5(3):233-238

Karaman ME, Pashley RM, Waite TD, Hatch SJ, Bustamante H (1997) A comparison of the interaction forces between model alumina surfaces and their colloidal properties. Colloids Surf A 129:239-255

Kleinstreuer C, Feng Y (2011) Experimental and theoretical studies of nanofluid thermal conductivity enhancement: a review. Nanoscale Res Lett 6:1-13

Kole M, Dey TK (2010a) Experimental investigation on the thermal conductivity and viscosity of engine coolant based alumina nanofluids. AIP Conf Proc 1249(1):120-124

Kole M, Dey TK (2010b) Thermal conductivity and viscosity of $\mathrm{Al}_{2} \mathrm{O}_{3}$ nanofluid based on car engine coolant. J Phys D Appl Phys 43(31):315501 
Lee JH, Hwang KS, Jang SP, Lee BH, Kim JH, Choi SU, Choi CJ (2008) Effective viscosities and thermal conductivities of aqueous nanofluids containing low volume concentrations of $\mathrm{Al}_{2} \mathrm{O}_{3}$ nanoparticles. Int $\mathrm{J}$ Heat Mass Transf 51(11):2651-2656

Li CH, Peterson GP (2006) Experimental investigation of temperature and concentration variations on the effective thermal conductivity of nanoparticle suspensions (nanofluids). J Appl Phys 99:084314

Lin JY, Pate MB (1992) A thermal conductivity prediction method for refrigerant mixtures in the liquid phase. IRACC 175

Lotfizadeh Dehkordi B, Kazi S, Hamdi M (2013a) Viscosity of ethylene glycol + water based $\mathrm{Al}_{2} \mathrm{O}_{3}$ nanofluids with addition of SDBS dispersant processing and properties of advanced ceramics and composites V. Cereal Chem 240:211-218

Lotfizadeh Dehkordi B, Kazi SN, Hamdi M, Ghadimi A, Sadeghinezhad E, Metselaar HSC (2013b) Investigation of viscosity and thermal conductivity of alumina nanofluids with addition of SDBS. Int J Heat Mass Transf 49(8):1109-1115

Maïga SEB, Nguyen CT, Galanis N, Roy G, Maré T, Coqueux M (2006) Heat transfer enhancement in turbulent tube flow using $\mathrm{Al}_{2} \mathrm{O}_{3}$ nanoparticle suspension. Int $\mathrm{J}$ Numer Method $\mathrm{H}$ 16(3):275-292

Malviya RK, Verma M, Yadav V (2013) Preparation and characterization of zinc oxide nano fluids in organic components. Sci Technol Manag J 187:2738-2740

Manikandan S, Jancirani J (2014) Heat transfer enhancement of thermal system using nanofluids. J Chem Pharma Sci 974:2115

Maxwell JC (1954) A treatise on electricity and magnetism, vol 1, 3rd edn. Dover, New York, p 435

Mintsa HA, Roy G, Nguyen CT, Doucet D (2009) New temperature dependent thermal conductivity data for water-based nanofluids. Int J Therm Sci 48(2):363-371

Mishra PC, Nayak SK, Mukherjee S (2013) Thermal conductivity of nanofluids-an extensive literature review. Int J Eng Res Technol 2:734-745

Moghadassi AR, Hosseini SM, Henneke DE (2010) Effect of CuO nanoparticles in enhancing the thermal conductivities of monoethylene glycol and paraffin fluids. Ind Eng Chem Res 49:1900-1904

Neethumol V, Manjusha H, Benny Cherian A, Sreenivasan PV, Paul J, Asmy Antony KA (2014) PVA-assisted synthesis and characterization of nano $\alpha$-alumina. Int J Sci Res 4(10):2250-3153

Nguyen CT, Desgranges F, Galanis N, Roy G, Mare T, Boucher S, Mintsa HA (2008) Viscosity data for $\mathrm{Al}_{2} \mathrm{O}_{3}$ /water nanofluidhysteresis: is heat transfer enhancement using nanofluids reliable? Int J Therm Sci 47:103-111

Patel HE, Sundararajan T, Das SK (2010) An experimental investigation into the thermal conductivity enhancement in oxide and metallic nanofluids. J Nanopart Res 12(3):1015-1031

Pathania D, Katwal R, Kaur H (2016) Enhanced photocatalytic activity of electrochemically synthesized aluminum oxide nanoparticles. Int J Miner Metall Mater 3(23):358-371

Sathyaseelan B, Baskaran I, Sivakumar K (2013) Phase transition behavior of nanocrystalline $\mathrm{Al}_{2} \mathrm{O}_{3}$ powders. Soft Nanosci Lett 3(04):69

Saxena SK, Pendharkar JK, Ghalsasi Y (2013) Acoustic parameters of potassium halides with variable normality. Int Interdiscip J Res 3:2249-9598
Senthilraja S, Vijayakumar KCK, Gangadevi RA (2015) comparative study on thermal conductivity of $\mathrm{Al}_{2} \mathrm{O}_{3}$ /water, $\mathrm{CuO}$ /water and $\mathrm{Al}_{2} \mathrm{O}_{3}-\mathrm{CuO}$ /water nanofluids. Dig $\mathrm{J}$ Nanomater Biostruct 10:1449-1458

Shah J, Gupta SK, Sonvane Y, Davariya V (2017) Enhancing efficiency of solar thermal engineering systems by thermophysical properties of a promising nanofluids. Renew Sustain Energy Rev 77:1343-1348

Sundar LS, Farooky MH, Sarada SN, Singh MK (2013a) Experimental thermal conductivity of ethylene glycol and water mixture based low volume concentration of $\mathrm{Al}_{2} \mathrm{O}_{3}$ and $\mathrm{CuO}$ nanofluids. Int Commun Heat Mass Transf 41:41-46

Sundar LS, Farooky MH, Sarada SN, Singh MK (2013b) Experimental thermal conductivity of ethylene glycol and water mixture based low volume concentration of $\mathrm{Al}_{2} \mathrm{O}_{3}$ and $\mathrm{CuO}$ nanofluids. Int J Heat Mass Transf 41:41-46

Sundar LS, Ramana EV, Singh MK, Sousa AC (2014) Thermal conductivity and viscosity of stabilized ethylene glycol and water mixture $\mathrm{Al}_{2} \mathrm{O}_{3}$ nanofluids for heat transfer applications: an experimental study. Int J Heat Mass Transf 56:86-95

Timofeeva EV, Gavrilov AN, McCloskey JM, Tolmachev YV, Sprunt S, Lopatina LM, Selinger JV (2007) Thermal conductivity and particle agglomeration in alumina nanofluids: experiment and theory. Phys Rev E 76:061203

Wallin E, Selinder TI, Elfwing M, Helmersson U (2008) Synthesis of $\alpha-\mathrm{Al}_{2} \mathrm{O}_{3}$ thin films using reactive high-power impulse magnetron sputtering. EPL 82(3):36002

Wang XQ, Mujumdar AS (2007) Heat transfer characteristics of nanofluids: a review. Int J Therm Sci 46:1-19

Wang XJ, Zhu DS (2009) Investigation of $\mathrm{pH}$ and SDBS on enhancement of thermal conductivity in nanofluids. Chem Phys Lett 470:107-111

Wang LQ, Zhou XS, Wei XH (2008) Heat conduction mathematical models and analytical solutions. Springer, Berlin

Wong KV, De Leon O (2010) Applications of nanofluids: current and future. Adv Mech Eng 2:519659

Xie H, Wang J, Xi T, Liu Y, Ai F, Wu Q (2002a) Thermal conductivity enhancement of suspensions containing nanosized alumina particles. J Appl Phys 91:4568-4572

Xie H, Wang J, Xi T, Liu Y, Ai F, Wu Q (2002b) Thermal conductivity enhancement of suspensions containing nanosized alumina particles. J Appl Phys 91:4568-4572

Yi JH, Sun YY, Gao JF, Xu CY (2009) Synthesis of crystalline $\gamma$ $\mathrm{Al}_{2} \mathrm{O}_{3}$ with high purity. Met Soc China 19(5):1237-1242

Zamzamian A, Oskouie SN, Doosthoseini A, Joneidi A, Pazouki M (2011) Experimental investigation of forced convective heat transfer coefficient in nanofluids of $\mathrm{Al}_{2} \mathrm{O}_{3} / \mathrm{EG}$ and $\mathrm{CuO} / \mathrm{EG}$ in a double pipe and plate heat exchangers under turbulent flow. Exp Therm Fluid Sci 35(3):495-502

Zhu HT, Lin YS, Yin YSA (2004) novel one-step chemical method for preparation of copper nanofluids. J Colloid Interface Sci 277:100-103

\section{Publisher's Note}

Springer Nature remains neutral with regard to jurisdictional claims in published maps and institutional affiliations. 